\title{
Empty Sella Syndrome Presenting as Panhypopituitarism in a Child : A Case Report
}

\author{
Sharmin-Jahan'1, Masfiq-Ul-Hasan'1, Nusrat-Sultana' ${ }^{1}$, Md. Fariduddin ${ }^{2}$, Mohammad Enayet-Hussain ${ }^{3}$, M A \\ Hasanat $^{2}$
}

${ }^{1}$ Resident, Department of Endocrinology, BSMMU, ${ }^{2}$ Professor, Department of Endocrinology, BSMMU, ${ }^{3}$ Department of Neurology, Dhaka Medical College Hospital, ${ }^{2}$ Professor, Department of Endocrinology, BSMMU.

\begin{abstract}
:
Empty Sella refers to the absence or relative absence of the pituitary gland on radiologic imaging of the Sella turcica. This is usually an incidental finding, and as few as $10 \%$ patients presents with Hypopituitarism. The authors report a $13.5-$ year- old boy who presented with short stature and absence of signs of pubertal onset. Hormonal assay showed panhypopituitarism. X-ray left wrist joint showed delayed bone age and finally MRI of the brain revealed empty Sella. Growth hormone replacement therapy was started to increase the height. The boy is now on regular follow up to monitor response to treatment.
\end{abstract}

Key word: Panhypopituitarism, Empty Sella Syndrome

[BSMMU J $2013 ; 6(1): 58-61]$

\section{Introduction:}

The term Empty Sella syndrome (ESS) was first applied to an anatomic finding at autopsy by Busch in $1951 .{ }^{1}$ It is of two types; Primary Empty Sella syndrome is usually asymptomatic occurring in obese, multiparous, hypertensive women. Secondary ESS is the result of infarction, surgical removal, irradiation into a tumour, posthypophysitis etc. ${ }^{2}$ ESS is a rare presentation in children marked by clinically significant abnormalities.

We report a rare case of ESS in a young boy presenting with panhypopituitarism. The evaluation, management along with therapeutic approach, monitoring is discussed subsequently.

\section{Case Report:}

A 13.5- year- old boy (Fig-1) presented at Endocrine Discipline of Bangabandhu Sheikh Mujib Medical University (BSMMU) with the complaint failure to thrive. He was born full term via normal vaginal delivery to a 22 year old mother. His height lagged behind his peers since early childhood, yet growth velocity was normal without any superimposed acute change. Lack of any pubertal development was another reason for medical referral. $\mathrm{He}$

Address of correspondence: Dr. M A Hasanat, MBBS, M.Phil, MD Associate Professor of Endocrine Medicine, Department of Medicine, Bangabandhu Sheikh Mujib Medical University, Dhaka-1000, Bangladesh had normal developmental milestones and intelligence was apparently normal. He had no history of any significant chronic illness, psychological deprivation, drug therapy or family history, visual problem or headache.

On physical examination, his weight was $24 \mathrm{~kg}\left(0 \mathrm{n}\right.$ the $50^{\text {th }}$ percentile for weight for age chart), BMI- $18.75 \mathrm{~kg} / \mathrm{m}^{2}$ height $111 \mathrm{~cm}$ (on $5^{\text {th }}$ centile for height for age chart), arm span $112 \mathrm{~cm}$, crown to pubis was $56 \mathrm{~cm}$, and pubis to heel was $55 \mathrm{~cm}$ with a ratio of 1.018 . He had high pitched voice, absence of hair over face, axillae and leg. He had sparse pubic hair (Tanner stage-1). His testicular volume was $<1 \mathrm{ml}$ and stretched penile length was $3 \mathrm{~cm}$. His father's height was $152 \mathrm{~cm}$ and mother's height $162 \mathrm{~cm}$. thereby his target Midparental height was $163.5 \mathrm{~cm}$, which was unlikely to be achieved. All other systemic examinations were normal.

Routine haematological and biochemical investigations were done to exclude chronic systemic illness. $\mathrm{X}$ ray left wrist joint showed delayed bone age of 8-9 years (Fig-2), $\mathrm{X}$-ray skull lateral view was normal. Hormonal assay results included serum $\mathrm{LH}, \mathrm{FSH}$, testosterone $\mathrm{TSH}, \mathrm{FT}_{4}$, GH before and after stimulation, basal cortisol, plasma ACTH and serum prolactin were done which showed panhypopituitarism (Table-I). MRI of the brain revealed empty Sella (Fig-3). 


\section{Table-I}

Hormonal assay of the patient

\begin{tabular}{lcc}
\hline Hormones & Patient values & Normal values \\
\hline Serum GH(before exercise) & $0.17 \mathrm{ng} / \mathrm{ml}$ \\
Serum GH(after exercise) & $0.056 \mathrm{ng} / \mathrm{ml}$ \\
Serum LH & $0.95 \mathrm{mIU} / \mathrm{ml}$ \\
Serum FSH & $1.10 \mathrm{mIU} / \mathrm{ml}$ \\
Serum testosterone & $35.5 \mathrm{ng} / \mathrm{dl}$ \\
Serum TSH & $8.20 \mu \mathrm{IU} / \mathrm{ml}$ \\
Serum FT & $0.74 \mathrm{ng} / \mathrm{ml}$ \\
\hline
\end{tabular}

He was started on replacement with $\mathrm{GH}(0.035 \mathrm{mg} / \mathrm{kg}$ /day) daily at night by subcutaneous injection. It would be continued up to bone age 15 years or when growth rate $<2.5 \mathrm{~cm} /$ year. Replacement with tab thyroxin 50 micrograms/day each morning was also started. Gonadotropin replacement would be considered in subsequent followup.

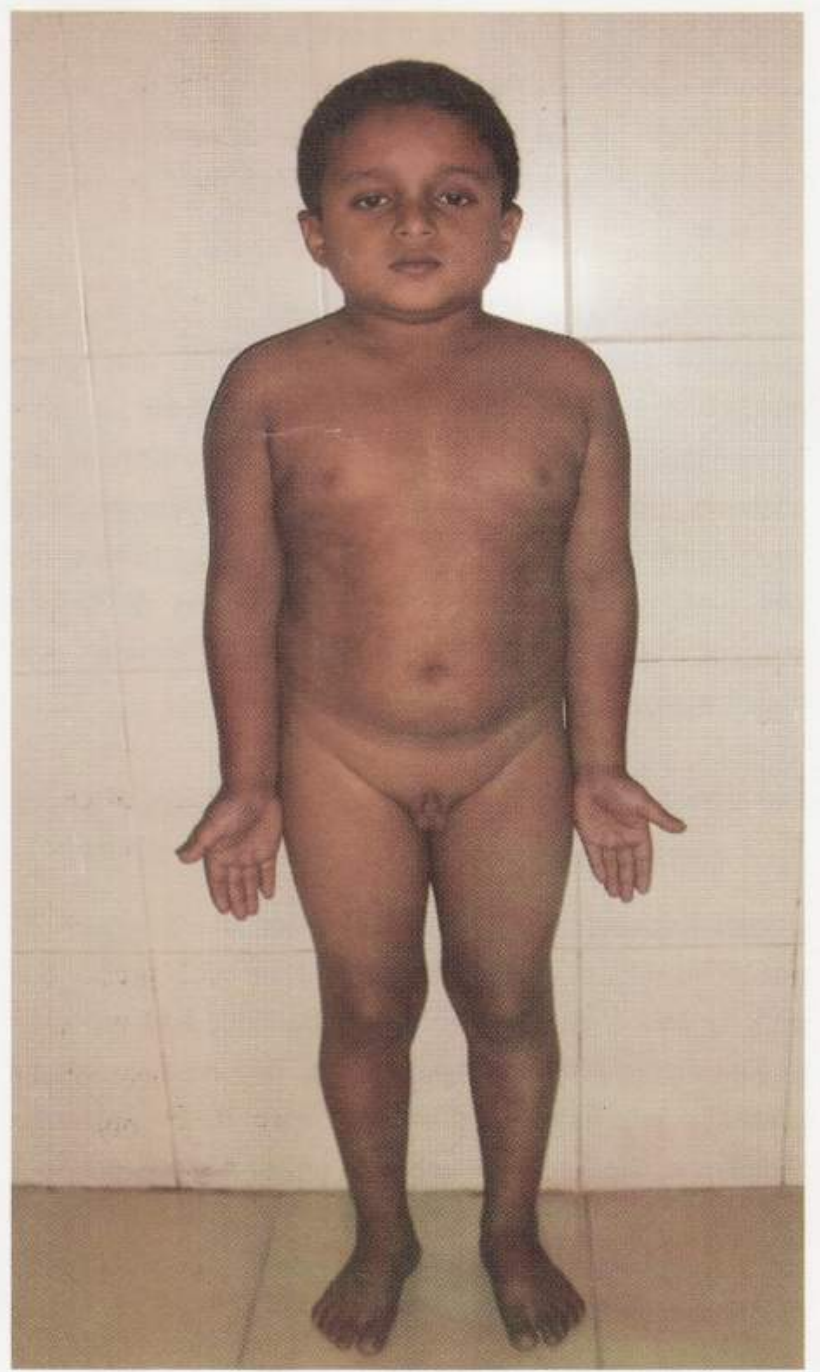

Fig-1 : Front profile of the patient.

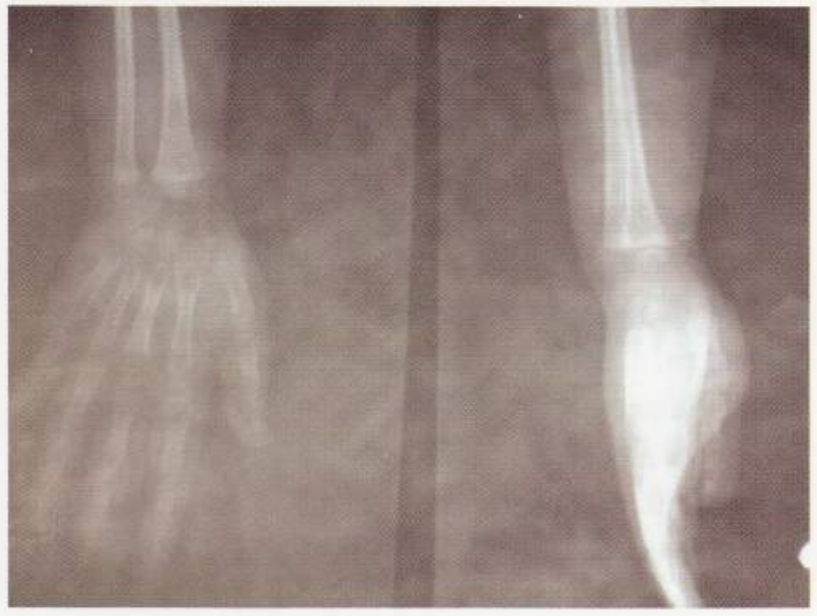

Fig-2: X-ray of left wrist joint shows a bone age of 8-9 years.

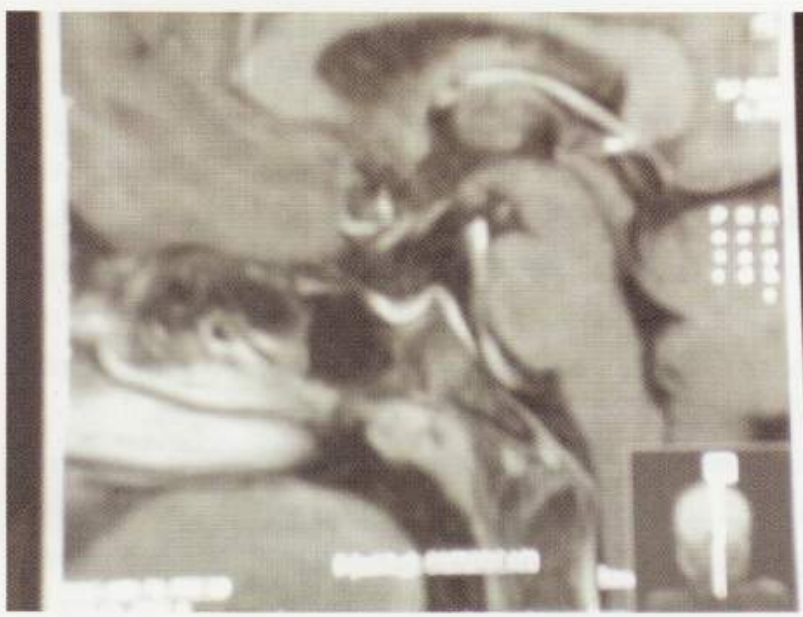

Fig-3: MRI of brain (Sagittal view) shows an empty Sella.

\section{Discussion:}

ESS is a disorder that involves the Sella turcica, a bony structure with resemblance to Turkish saddle, at the base of the brain that surrounds and protects the pituitary gland. ${ }^{2}$ It is a condition that is often discovered during tests for pituitary disorders, when neuroradiologic imaging reveals a Sella that appears to be partially or completely empty. The term empty Sella was first applied to an anatomic finding at autopsy by Busch in $1951 .{ }^{1} \mathrm{He}$ found that in 40 patients with no known pituitary disease, the pituitary gland was severely compressed against the floor of the Sella (5.6\% of the series) and the diaphragm Sellae was restricted to a thin rim of tissue around a huge infundibulur foramen. Busch also pointed out that an empty Sella was far more frequent in females than in males (34:6). ${ }^{1}$ It is of two types. Primary empty Sella is 
probably a normal variant or perhaps result from a congenital defect in diaphragm Sella. The Sella is not actually empty but contains CSF; the pituitary gland is flattened against the walls of the Sella. Contemporary series suggest that the presence of an empty Sella is fairly common ( 8 to 35 percent of the population), yet less than a third of individuals with the condition ever develop symptoms. Clinical studies of the symptomatic patients with primary empty Sella syndrome have revealed a variety of associated problems, and it seems likely that several etiologic factors are involved in producing an empty Sella. Despite this diversity, patients with primary empty Sella syndrome are a surprisingly homogeneous group. Over $80 \%$ of these patients are women, and the majority become symptomatic in the decade from age 40 to 49 , with over $80 \%$ presenting between 30 and 59 years of age. An intrasellar problem is seldom suspected when the diagnostic studies are started. ${ }^{1}$ The Syndrome is usually asymptomatic and occurs in obese, multiparous, hypertensive women who experience headache but have no underlying neurologic disorder. Initial complaints in primary ESS fall into 3 categories: neurologic, endocrinologic and systemic. Headache is the most common symptom $(50 \%-80 \%)$, others are memory loss, balance impairment, dizziness, seizure, rhinorrhoea, papilloedema, reduced visual acuity, visual field loss $(10 \%)$. Endocrine complaints leading to investigation include amenorrhoea, galactorrhoea, loss of libido, Diabetes Insipidus. Systemic complaints such as obesity and hypertension lead to radiologic studies. ${ }^{1}$

By comparison, the rare presentation of ESS in children is usually marked by clinically significant abnormalities (45\%-75\%), craniofacial abnormalities $(30 \%)$, visual complaints $(35 \%)$. Small number of patients presented with precocious puberty, diabetes Insipidus (DI), growth hormone deficiency, headache $(3 \%)$, or non-specific systemic complaints $(4 \%)$.

On the other hand secondary ESS is the result of infarction, surgical removal, irradiation into a tumour, posthypophysitis (e.g.: neurosarcoidosis) rarely. It is associated with abnormal secretion of growth hormone $(\mathrm{GH})$, prolactin (PRL) and adrenocorticotropic hormone (ACTH). ${ }^{1}$ Presence of panhypopituitarism has been as high as $10 \%$. Significantly altered pituitary stimulation tests are noted in 30 to $50 \%$ of these patients. The most commonly observed abnormality $(30 \%)$ has been deficient GH secre- tion during stimulation tests. Abnormalities in the secretion of ACTH (11\%), luteinizing hormone ( $\mathrm{LH})$, and thyroid-stimulating hormone (TSH, 15\%) have also been reported in association with an empty sella. ${ }^{1}$

Our patient presented with short stature and lack of pubertal development, but with apparent normal intelligence. Delayed bone age, reduced growth velocity $(<3$ SD below mean), height not projecting within parental target range essentially ruled out the possibility of and familial short stature. Also history and clinical presentation were not suggestive of any chronic illness or syndromic appearance. So he was suspected of having either isolated growth hormone deficiency or panhypopituitarism, Hormonal assay proved the latter one (the deficient hormones were $\mathrm{GH}$ and Gonadotropin) though serum $\mathrm{ACTH}$ and basal cortisol were within normal range. To find out the underlying aetiology, MRI of the brain was done which showed empty Sella. He was later started on growth hormone replacement therapy contemplated to be continued up to the age of 15 years or when the growth velocity will be less than $2.5 \mathrm{~cm} /$ year, add on therapy with Gonadotropin at a later age to prime puberty is also planned.

Robert Rapaport et al. reported a case of 7.5 -year- old girl with Gonadotropin dependent central precocious puberty and a partially empty Sella who had no other hypothalamic-pituitary dysfunction. Involvement of the posterior pituitary gland is very rare in Empty Sella Syndrome. Wellington Hung et al report a seven-year-old girl with empty-Sella syndrome who first developed arginine-vasopressin deficient Diabetes Insipidus and then anterior pituitary gland deficiency. ${ }^{3}$

Our case demonstrates one of the unique ways of empty Sella with panhypopituitarism presenting in a young boy.

Robert Rapaport et al. reported a case of 7.5 -year- old girl with Gonadotropin dependent central precocious puberty and a partially empty Sella who had no other hypothalamic-pituitary dysfunction. Involvement of the posterior pituitary gland is very rare in Empty Sella Syndrome. Wellington Hung et al report a seven-year-old girl with empty-Sella syndrome who first developed arginine-vasopressin deficient Diabetes Insipidus and then anterior pituitary gland deficiency. ${ }^{3}$

Our case demonstrates one of the unique ways of empty 
Sella with panhypopituitarism presenting in a young boy.

\section{Contributors:}

Sharmin-Jahan and Mashfiq-Ul-Hasan thoroughly examined and investigated the case under supervision of $\mathrm{M} \mathrm{A}$ Hasanat and Md. Fariduddin. They prepared the initial manuscript and endorsed important and pertinent references. M A Hasanat and Md. Fariduddin finally formatted the case for publication. Nusrat Sultana and Md. Enayet Hussain helped in preparing the Case report all through. All the authors have gone through and contributed to the final manuscript.

\section{References:}

1. Http:// pituitary adenomas.com/index.htm

2. Melmed S and Kleinberg D. Anterior pituitary. In: Kronenberg HM, Melmed S, Polonsky KS, Larsen PR, eds. Williams Textbook of Endocrinology. Philadelphia, PA: Saunders Elsevier; 2008: chap 8.

3. Rapaport R and Logrono R. Primary Empty Sella Syndrome in Childhood: Association with Precocious Puberty. Clin Pediatr 1991; 30: 466-71 